\title{
Shell shape variation and fitness variables in the gastropod Littorina saxatilis
}

\author{
Thomas N. Walker ${ }^{1}$, John W. Grahame ${ }^{2, *}$ \\ ${ }^{1}$ Yorkshire Dales Estate Office, Waterhouses, Malham Tarn, Settle BD24 9PT, UK \\ ${ }^{2}$ Institute of Integrative \& Comparative Biology, University of Leeds, Leeds LS2 9JT, UK
}

\begin{abstract}
On shores on the east coast of Yorkshire, England, the gastropod Littorina saxatilis shows consistency in shell shape variation in samples taken from the upper portion of its intertidal range. Using analysis of shell dimensions by standard multivariate techniques and extended eigenshape analysis, this variation can be dissected into different aspects, and related to the 'Raup growth parameters'. Some of the shell variation is shown to be related to the relative proportions of body and brood mass, and to an estimate of reproductive effort. This implies an association (perhaps indirect) between subtle variations in shell shape and fitness variables.
\end{abstract}

KEY WORDS: Shell shape $\cdot$ Fitness $\cdot$ Littorina $\cdot$ Trade-offs

Resale or republication not permitted without written consent of the publisher

\section{INTRODUCTION}

The intertidal environment is one which demands of the organisms that live in it the successful resistance of considerable stress. Primarily marine organisms are exposed to desiccation, extremes of temperature, wetting by rain and wave action to a greater degree than are marine inhabitants of the sublittoral or the pelagic. They are favourite subjects for the study of adaptation in terms of morphology, physiology, life history and phenotypic plasticity. Among intertidal animals, shelled gastropods are very attractive precisely because they have a shell which is so vital in the life of the animal, while presenting a set of features convenient for study. Among shelled gastropods, Littorina saxatilis (Olivi) has attracted a great deal of attention. Shell shape is very variable in this species; it is considered the most variable in the genus Littorina (Reid 1996). There is evidence that at least some of this variation may be adaptive in resisting wave action (Grahame \& Mill 1986) or desiccation (Grahame et al. 1990). Atkinson \& Newbury (1984) related such variation to life history strategy, as did Hart \& Begon (1982). Hughes (1995) took an experimental approach, showing that when $L$. saxatilis was starved, growth was reduced; this was more severe in repro- ductive snails, indicating relative protection of allocation to reproduction.

Such experiments lead to considerations of how much a currently observed state or feature may be due to phenotypic plasticity. Studies using Littorina species have played their part here too. Current understanding is that what are called 'genetic determination' and 'plastic response' are both involved, with the former being at least as important and usually most important in determining shell shape. For example, a recent estimate is that 72 to $99 \%$ of adaptive shape variation in $L$. saxatilis on Galician shores was due to ecotype irrespective of growth environment (Conde-Padín et al. 2009).

For many of these studies, measurement of shape is crucial. Frequently, workers have used points on the shell between which linear dimensions are measured and analysed using conventional multivariate analytic methods (e.g. Caley et al. 1995, Grahame et al. 2006). An alternative approach, but starting perhaps with the same points, is to use a geometric morphometric method such as thin-plate spline analysis (CondePadin et al. 2007). A potential difficulty with such approaches is the placing of the points: an outline of a gastropod shell may not offer many truly homologous points which can be unambiguously determined across 
a series of shells. It is appealing in this circumstance to use an outline-based method, perhaps Fourier coefficients, applied to Littorina spp. by Dytham et al. (1992), or the more recently developed eigenshape and extended eigenshape methods (MacLeod 1999, Krieger et al. 2007).

In Littorina (as in the great majority of molluscs), the realised shape of the shell is determined by incremental growth at the margin of the mantle, morphologically the snail's anterior. Raup (1966) developed a model for shell growth that is able to describe the form of molluscs using 4 parameters: $W, T, S$ and $D$. Imagining the aperture of a gastropod to be where the shell is formed by incremental growth, the shape of the aperture is measured by $S$, the 'generating curve'. This generating curve rotates round a coiling axis, and if it moves along this axis, a shell with a spire is formed (e.g. the turbinate form of Littorina); the rate of movement along the axis is the translation rate, $T$. The area enclosed by the generating curve gets larger according to the expansion rate, $W$. Finally, the generating curve may move outward away from the coiling axis at a rate $D$. This model is admittedly simple and general (Raup 1966), yet it adequately describes much of the realised shape of molluscs, leaving aside questions such as sculpturing and shell thickness. For real shells to work, changes in 1 parameter may have to be accommodated by changes in others (e.g. Clarke et al. 1999). The Raup growth model provides a framework for considering mollusc shell form which is less abstract than the statistics of multivariate analysis. The 2 can be synthesised, at least to a degree, by using data sets where at least some of the linear measures can be used to estimate Raup growth parameters.

This paper explores the variation in shells of Littorina saxatilis collected from a very restricted part of its range, viz. the high intertidal of 3 shores on the east Yorkshire (UK) coast. We use 2 of the shape-analytic approaches referred to above, namely principal component analyses (PCA) of linear dimensions of the shells, and the extended eigenshape method of MacLeod (1999). We consider the composite variables generated by PCA in relation to Raup parameters, and also in relation to the results of the eigenshape analysis. To seek biological significance, we relate the variation of the shell to estimates of allocation to body and to brood size, thus getting an approximate estimate of reproductive effort.

\section{MATERIALS AND METHODS}

Littorina saxatilis were collected from 4 sample sites on 3 shores on the east coast of Yorkshire in December and January; the species breeds all year at these loca- tions (Hull et al. 1999). The sites were Selwicks Bay (British National Grid [BNG] TA254707) and Thornwick Bay (BNG TA233724), 2.5 km apart on Flamborough Head; and Old Peak (BNG NZ984021), ca. 41 km northwest along the coast from Flamborough Head. At this site, we used 2 sample locations (A and B) about $250 \mathrm{~m}$ apart. Collections were from pits and crevices in either bedrock cliff (Flamborough) or high-shore large boulders (Old Peak), taking snails from within about 1 to $2 \mathrm{~m}^{2}$ of rock. Thus in this work we refer only to variation within the $\mathrm{H}$ morph referred to by Hull et al. (1999).

In the laboratory, snails were killed by brief immersion in boiling water and either processed immediately or frozen $\left(-25^{\circ} \mathrm{C}\right)$ and worked with subsequently. For each snail, the body was removed from the shell, ensuring that the entire body was removed. For gravid female Littorina saxatilis, shell, body (less operculum) and brood pouch were dried at $60^{\circ} \mathrm{C}$ for $24 \mathrm{~h}$ and then weighed to $0.01 \mathrm{mg}$. Brood pouches were used if they appeared to be full of embryos. Those few which had a small number ( 10 or fewer) of embryos were discarded. No other control over brood pouch size was attempted. Great care was taken to exclude males and any females of $L$. arcana Hannaford Ellis.

For morphometrics, shells were carefully oriented in the way standard in our laboratory. Essentially, this method requires that the columella axis is horizontal, and at $90^{\circ}$ to this, the axis across the shell is made horizontal at its widest extent. This results in the aperture facing upwards with its plane at some degrees off the horizontal. In this orientation, shells were imaged digitally. We used the software TpsUtil and TpsDig (Rohlf 1996) to place points on the shell images, again using the pattern which is standard in our laboratory. From the coordinates of these points, we took linear dimensions as shown in Fig. 1. Estimates for the Raup parameters $W, T$ and $S$ can be derived from these dimensions: $W$ is ww1/ww2, $T$ is $\mathrm{cl} / \mathrm{ww} 1$, and $S$ is al/aw, where ww1 and ww2 are whorl widths 1 and 2, cl is columella length, al is aperture length, and aw is aperture width (Fig. 1; see also Clarke et al. 1999). We cannot adequately estimate $D$ from our data.

Analysis of the linear dimension data was carried out using PCA in either SAS (SAS Institute 1990) or R (R Development Core Team 2010), transforming the raw measures to logarithms of the ratio of any given dimension divided by the geometric mean of all linear dimensions. This procedure has been adopted to minimise the effect of size as such on the analysis, following Grahame \& Mill (1989). It was further explored by Darroch \& Mosimann (1985) and by Jungers et al. (1995), who referred to it as the 'DM_LOG' approach. Here, we denote transformed variables with a subscripted t. We calculated an index of aperture size, taking the area of 


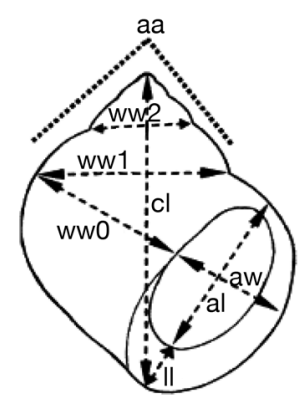

Fig. 1. Littorina saxatilis. Shell dimension variables used for the principal component analysis approach to shape measurement, and from which estimates of the Raup growth parameters may be calculated (see 'Materials and methods'). The dimensions taken are columella length (cl), lip length (ll), aperture length and width (al, aw), whorl widths 0,1 and 2 (www0, ww1, ww2), and the apical angle (aa). Modified after Grahame et al. (2006)

the aperture estimated from its length and width and dividing this by the square of the geometric mean size. This in effect expresses aperture area in the same framework as the linear dimensions standardised by geometric mean size; we call this variable the aperture index. Thus we used 2 variables expressing properties of the aperture: its circularity or shape (which relates to $S$ ) and aperture index (which relates to its size as a linearised estimate).

PCA yields a set of eigenvalues, i.e. numbers which express the variance in the data in a diminishing series, and each of which has an associated eigenvector consisting of coefficients relating the standardised variables to the components. We will thus refer here to coefficients of the eigenvectors. For each shell in the analysis, a score may be calculated which relates it to one or another principal component (PC); thus, we will refer to PC scores.

In a further analysis of outline shape, we made black and white versions of the shell images and outlined these in TpsDig (Rohlf 1996) using 450 coordinate points and defining 1 apical landmark point. This landmark served to provide a common starting point for anextended eigenshape analysis of the outlines (MacLeod 1999, Krieger et al. 2007). If such a landmark is not used, much of the variation detected in the analysis concerns rotation of the outlines.

Eigenshape analysis generates vectors of numbers referred to as eigenscores, values which relate the shells to the axes defined in the analysis. In this respect, they are analogous to PC scores, and must be distinguished from the eigenvalues and the eigenvectors of a conventional PCA.
With estimates of shape, we could place each shell on an axis-either a PC axis, or an axis of eigenscores - reflecting its shape relative to other members of the set. For each shell, we also had estimates of the supposedly biologically important variables of body and brood masses, as surrogates for somatic and reproductive function. We could now seek relationships between shape of the shell and body or brood mass. A difficult problem here is that all the variables are capable of change: there is no invariant standard to which to relate, e.g. body mass. We addressed this by standardising body and brood masses by shell mass to obtain ratios that we refer to as body index and brood index, respectively, and then standardising brood mass by body mass, obtaining another ratio referred to as reproductive effort (RE). This is necessarily a proxy measure of RE, which should be determined as the fraction of assimilated energy directed towards reproduction (e.g. see Hughes \& Roberts 1980).

Concerning multiple testing, which is an issue when, for example, we are seeking correlations between the tissue indices and shape, we are mindful of the considerations of Rosenthal (1978) and Moran (2003) in paying attention to the pattern of observation of 'significant' correlations. We have also included Bonferroni corrections.

\section{RESULTS}

Sample sizes and basic statistics are shown in Table 1. The snails were all of very similar mean size; as expected, the rather small changes in mean columella length $(\mathrm{cl})$ are reflected in somewhat larger variations in the mass measures. PCA using shell dimensions (excluding shell mass) showed considerable consistency between the samples. For each sample except that from Selwicks, there were 3 components with eigenvalues $>1$. At Selwicks, PC3 had an eigenvalue of only 0.86 .

Within any sample, the components ought to be uncorrelated, and this was found to be the case. However, if there is consistency in the variation between the samples, there ought to be similarities between components in the different analyses. Spearman rank

Table 1. Littorina saxatilis. Statistics for size and mass of snails. Values are means $\pm \mathrm{SE}$

\begin{tabular}{|lccccc|}
\hline Site & $\mathrm{n}$ & $\begin{array}{c}\text { Columella } \\
\text { length }(\mathrm{mm})\end{array}$ & $\begin{array}{c}\text { Body } \\
\text { mass }(\mathrm{g})\end{array}$ & $\begin{array}{c}\text { Brood } \\
\text { mass }(\mathrm{g})\end{array}$ & $\begin{array}{c}\text { Shell } \\
\text { mass }(\mathrm{g})\end{array}$ \\
\hline Selwicks & 38 & $8.08 \pm 0.27$ & $0.011 \pm 0.00071$ & $0.0022 \pm 0.00020$ & $0.059 \pm 0.0053$ \\
Thornwick & 56 & $8.36 \pm 0.17$ & $0.014 \pm 0.00087$ & $0.0031 \pm 0.00027$ & $0.088 \pm 0.0062$ \\
Old Peak A & 40 & $7.53 \pm 0.12$ & $0.011 \pm 0.00051$ & $0.0033 \pm 0.00026$ & $0.054 \pm 0.0036$ \\
Old Peak B & 18 & $9.62 \pm 0.26$ & $0.016 \pm 0.0011$ & $0.0059 \pm 0.00095$ & $0.15 \pm 0.016$ \\
\hline
\end{tabular}


correlation coefficients calculated using the coefficients for the variables on the components showed that there were indeed sometimes high correlations between those for the different samples. We carried out a multidimensional scaling analysis of the coefficients for the variables on the PCs, using 'cmdscale' in R. This gave an ordination shown in Fig. 2; this is a representation of the similarities between the PCs, which fall into 3 clear groups. Statistical data relating to Fig. 2 are shown in Table $\mathrm{S} 1$ in the supplement at www.intres.com/articles/suppl/m430p103_supp.pdf.

The strongest relationships were for the body index and PCs for the second group of vectors in Table S1, i.e. Selwicks PC1, Old Peak B PC3, Old Peak A PC2 and Thornwick PC2. These are characterised by having highest positive values for $\mathrm{ww}_{\mathrm{t}}$, and highest negative values for either lip length $\left(l_{t} ; 3\right.$ cases) or $\mathrm{ww} 2_{t}$ followed by $l_{t}$ (Old Peak B PC3). RE values related convincingly at 2 locations to PCs in this same group and for 1 location to a component in the first group (that for Old Peak A PC1).

In view of the fact that there is a high degree of consistency between the PCs and the relationships of standardised tissue variables to them, we next carried out a PCA on the shell dimension data pooled across samples, and calculated Spearman rank correlations between the standardised tissue variables and the shell scores on these 'global' components (Table 2).

Table 2 shows that there are 5 (of a total possible 12) relationships with $\mathrm{PC} 1$ that are significant at $\mathrm{p} \leq 0.05$, and all are negative, reflecting a decrease in the standardised tissue variable with shape along this component. PC2 shows only 1 such relationship, for body index at Selwicks $(p<0.001)$. The remaining relationship shown is for brood index at Old Peak B, which is not significant $(p=0.070)$. PC3, which accounts for relatively little of the total variation $(18 \%)$ shows 6 relationships with standardised tissue variables significant at $\mathrm{p} \leq 0.05$. Where the correlation is with body index, it is negative; where it is with $\mathrm{RE}$, it is positive, and there are no relationships with brood index. A Bonferroni correction for multiple testing on the rows in Table 2 reduces the number of significant correlations; a table-wide correction would eliminate significance.

Table 3 shows the coefficients for the variables making up the eigenvectors. Here we will refer to the transformed variables (see 'Materials and methods'), denoted with a subscripted t. PC1 is mainly

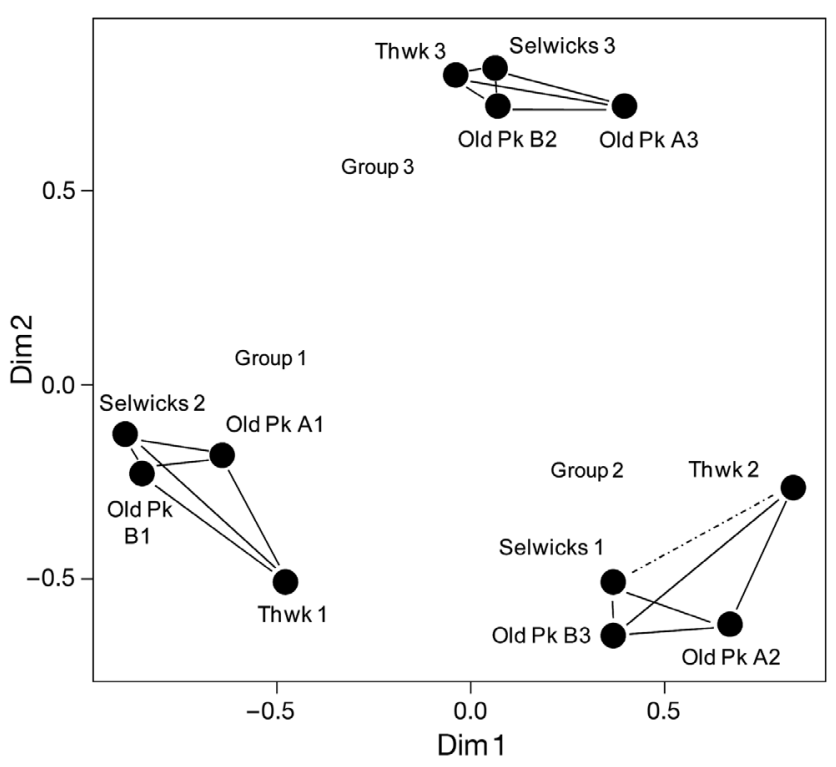

Fig. 2. Littorina saxatilis. First 3 principal components calculated from each of the 4 samples plotted on the first 2 dimensions of a multidimensional scaling analysis of the component vectors. Solid lines connect the symbols for the vectors between which the Spearman rank correlation is significant at $\mathrm{p} \leq 0.05$; the broken line shows the 1 instance where the correlation is weaker than this $(\mathrm{p}=0.083)$. Numerical data are given in Table $\mathrm{S} 1$ in the supplement

related to changes in $\mathrm{ww} 2_{\mathrm{t}}$ and $\mathrm{cl}_{\mathrm{t}}$ contrasted with the apical angle (aa). Of the Raup parameters $T, W$ and $S$, only $W$ correlates with PC1 ( $\rho=0.696, p<0.001)$. However, the derived variable aperture index (see 'Materials and methods') does correlate with this PC ( $\rho=$ 0.472, p < 0.001). Fig. 3 shows example shells from the negative and positive ends of PC1, together with a plot of $W$ and aperture index on the PC.

Table 2. Littorina saxatilis. Spearman rank correlations ( $\rho$ ) between tissue indices and shell principal component (PC) scores for the components calculated across all samples. Correlations with $\mathrm{p} \leq 0.003$ are shown in bold. This represents adjusting $\alpha$ to 0.003. Correlations with $\mathrm{p}>0.05$ are not shown

\begin{tabular}{|lcccccc|}
\hline & \multicolumn{3}{c}{ Brood index } & \multicolumn{2}{c}{ Body index } & \multicolumn{2}{c}{ Reproductive effort (RE) } \\
& $\rho$ & $p$ & $\rho$ & $p$ & $\rho$ & $p$ \\
\hline PC1 (2.98, 37 \%) & & & & & & \\
Thornwick & $\mathbf{- 0 . 4 2 6}$ & $\mathbf{0 . 0 0 1}$ & -0.383 & 0.004 & -0.278 & 0.038 \\
Old Peak A & -0.380 & 0.016 & - & - & -0.363 & 0.021 \\
PC2 (2.27, 28 \%) & & & & & & \\
Selwicks & - & - & $\mathbf{0 . 6 1 2}$ & $<\mathbf{0 . 0 0 1}$ & - & - \\
Pooled & 0.188 & 0.023 & $\mathbf{0 . 3 8 8}$ & $<\mathbf{0 . 0 0 1}$ & - & - \\
PC3 (1.47, 18\%) & & & & & & \\
Selwicks & - & - & -0.371 & 0.022 & 0.323 & 0.048 \\
Thornwick & - & - & -0.275 & 0.040 & - & - \\
Old Peak A & - & - & $-\mathbf{0 . 5 3 7}$ & $<\mathbf{0 . 0 0 1}$ & $\mathbf{0 . 4 7 4}$ & $\mathbf{0 . 0 0 2}$ \\
Old Peak B & - & - & $-\mathbf{0 . 6 9 9}$ & $\mathbf{0 . 0 0 1}$ & - & - \\
Pooled & - & - & $-\mathbf{0 . 5 0 8}$ & $<\mathbf{0 . 0 0 1}$ & 0.180 & 0.027 \\
\hline
\end{tabular}


Table 3. Littorina saxatilis. Variable coefficients in the eigenvectors (see 'Materials and methods') of the principal components (PCs) calculated across all samples. ww0, ww1, ww2: whorl widths 0,1 and 2; cl: columella length; ll: lip length; al: aperture length; aw: aperture width; aa: apical angle. Subscript $t$ indicates transformed variables (see 'Materials and methods')

\begin{tabular}{|c|c|c|c|c|c|}
\hline Variable & $\mathrm{PC} 1$ & Variable & PC2 & Variable & PC3 \\
\hline $\mathrm{ww} 2_{\mathrm{t}}$ & -0.524 & $l_{t}$ & -0.572 & $\mathrm{al}_{\mathrm{t}}$ & -0.506 \\
\hline $\mathrm{cl}_{\mathrm{t}}$ & -0.443 & $w w 2_{t}$ & -0.015 & $\mathrm{Cl}_{\mathrm{t}}$ & -0.331 \\
\hline$w w 1_{t}$ & -0.233 & $\mathrm{cl}_{\mathrm{t}}$ & 0.067 & $\mathrm{aw}_{\mathrm{t}}$ & -0.222 \\
\hline $\mathrm{wwO}_{\mathrm{t}}$ & -0.028 & aa & 0.110 & $w w 2_{t}$ & -0.146 \\
\hline$l_{\mathrm{t}}$ & 0.223 & $\mathrm{al}_{\mathrm{t}}$ & 0.330 & aа & 0.074 \\
\hline $\mathrm{aw}_{\mathrm{t}}$ & 0.249 & ww1t & 0.417 & $l_{\mathrm{t}}$ & 0.252 \\
\hline $\mathrm{al}_{\mathrm{t}}$ & 0.274 & $w w 0_{t}$ & 0.428 & $\mathrm{ww} 1_{\mathrm{t}}$ & 0.471 \\
\hline aа & 0.536 & $\mathrm{aw}_{\mathrm{t}}$ & 0.437 & $\mathrm{ww}_{\mathrm{t}}$ & 0.522 \\
\hline
\end{tabular}

As PC2 shows relatively little relationship with tissue variables, we neglect it here. PC3 contrasts $\mathrm{al}_{\mathrm{t}}$ (and to a lesser extent $\mathrm{cl}_{\mathrm{t}}$ and $\mathrm{aw}_{\mathrm{t}}$ ) with $\mathrm{ww}_{\mathrm{t}}$ and $\mathrm{ww} 1_{\mathrm{t}}$. Fig. 4 shows that along PC3, $W$ increases, $T$ decreases, and both aperture index and $S$ change-apertures become smaller, and the estimate of $S$ declines towards 1, thus apertures become more circular. All of these relationships are significant, as $\rho$ values have $p<0.001$ in these instances.

The results of an extended eigenshape analysis on the same shells were compared with the PCA, and similar features emerged in terms of relationships of shell to standardised tissue variables, both on a location-bylocation and a global basis. We will not deal with the first, but will discuss the global analysis. First of all, we found that using the eigenscores (EScs) of the shell outlines and correlating these with the shell scores on the PCs, there were many correlations which were very small and a few which were comparatively large. The strongest by far was that between ESc1 and PC1 (Table 4). After this, there is a comparatively weak correlation between $\mathrm{ESc} 3$ and $\mathrm{PC} 2$, and rather stronger ones between ESc3 and ESc4 and PC3. For the remaining EScs up to ESc10, there were 4 more correlations with PCs which were significant at $\mathrm{p} \leq 0.05 ; 2$ of these involved PC3, with ESc8 $(\rho=0.173, p=0.033)$ and ESc9 $(\rho=0.358, p<0.001)$. Thus in a total of 30 correlations between PCs and EScs, 4 involved PC3, and 4 were with the other 2 PCs. As with Table 2, Bonferroni correction based on the columns in Table 4 leaves significant correlations, while an analysis-wide correction would eliminate any significance.

Considering likely relationships between body, brood and shell sizes, PC1 showed evidence of such a relationship, with the standardised tissue variables decreasing along the PC (Table 2). However, the correlations are only significant at Thornwick and Old Peak A (and here for brood index and RE only). For these instances, this means that the tall shells exemplified by negative scores on this PC had relatively larger tissue masses than the squatter ones with positive scores (Fig. 3). This relationship is not evident in the pooled data correlations (Table 2).

ESc1 was strongly identified with PC1, and correlated with brood index $(\rho=0.418, p=0.007)$ and $R E$ $(\rho=0.422, p=0.007)$ at Old Peak A. Since the correlation between ESc1 and PC1 is itself negative, positive correlations between ESc1 and standardised tissue variables are consistent with negative ones between those variables and PC1. At Thornwick, the correlations with ESc1 were comparatively very weak at $\mathrm{p} \sim 0.06$. As with $\mathrm{PC} 1$, the relationships are not evident in the pooled data correlations.

Finally, we found that ESc4 and PC3 were evidently strongly related (Table 4). At Old Peak A and B there was evidence of the expected correlations with standardised tissue variables, although it was weak for body index at Old Peak B $(\rho=0.281, p=0.080)$. For the

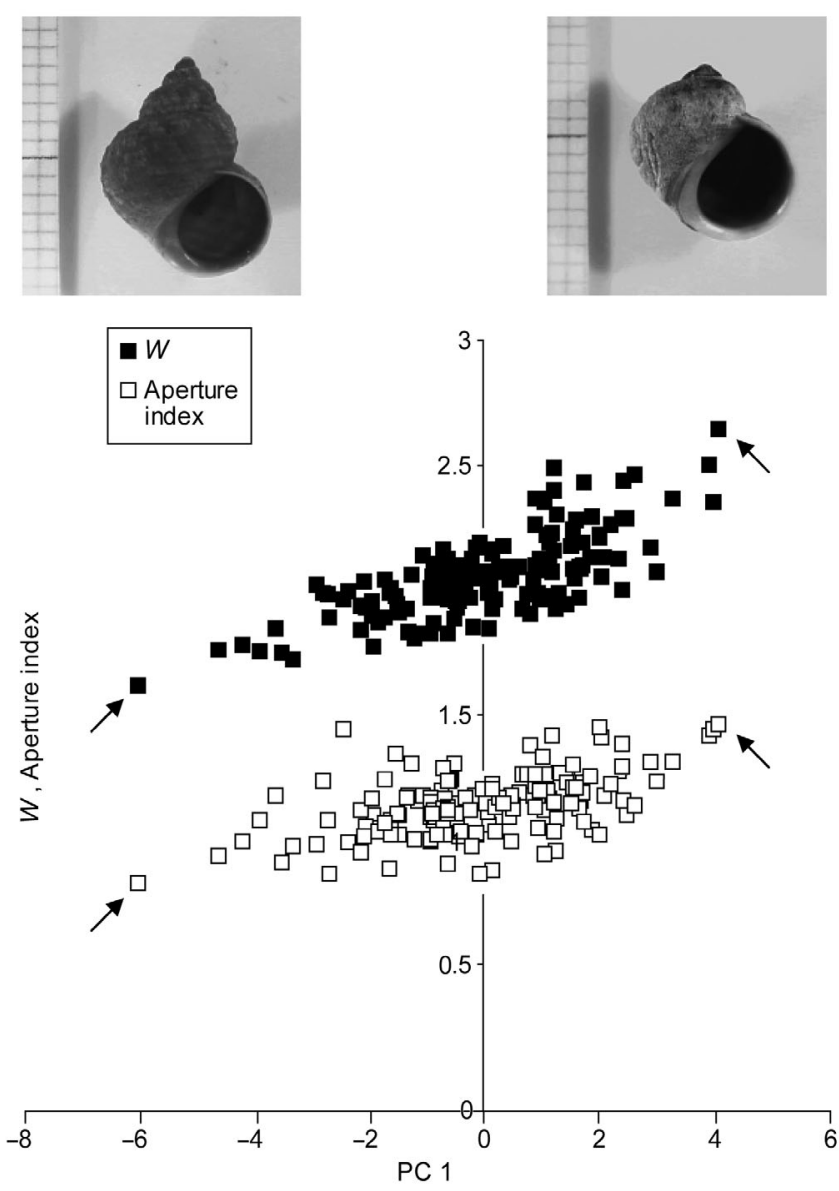

Fig. 3. Littorina saxatilis. Estimates of the Raup parameter $W$ and aperture index, plotted on scores for principal component (PC) 1. Example shells from the extremes of the component are shown; their positions on the plot are indicated by arrows 
pooled data, the correlation between ESc4 and body index was $0.268(\mathrm{p}=0.001)$, and the correlation with RE was $-0.262(p=0.001)$. Again, because the correlation between ESc4 and PC1 was negative, the signs of these correlations are consistent with those in Table 2.
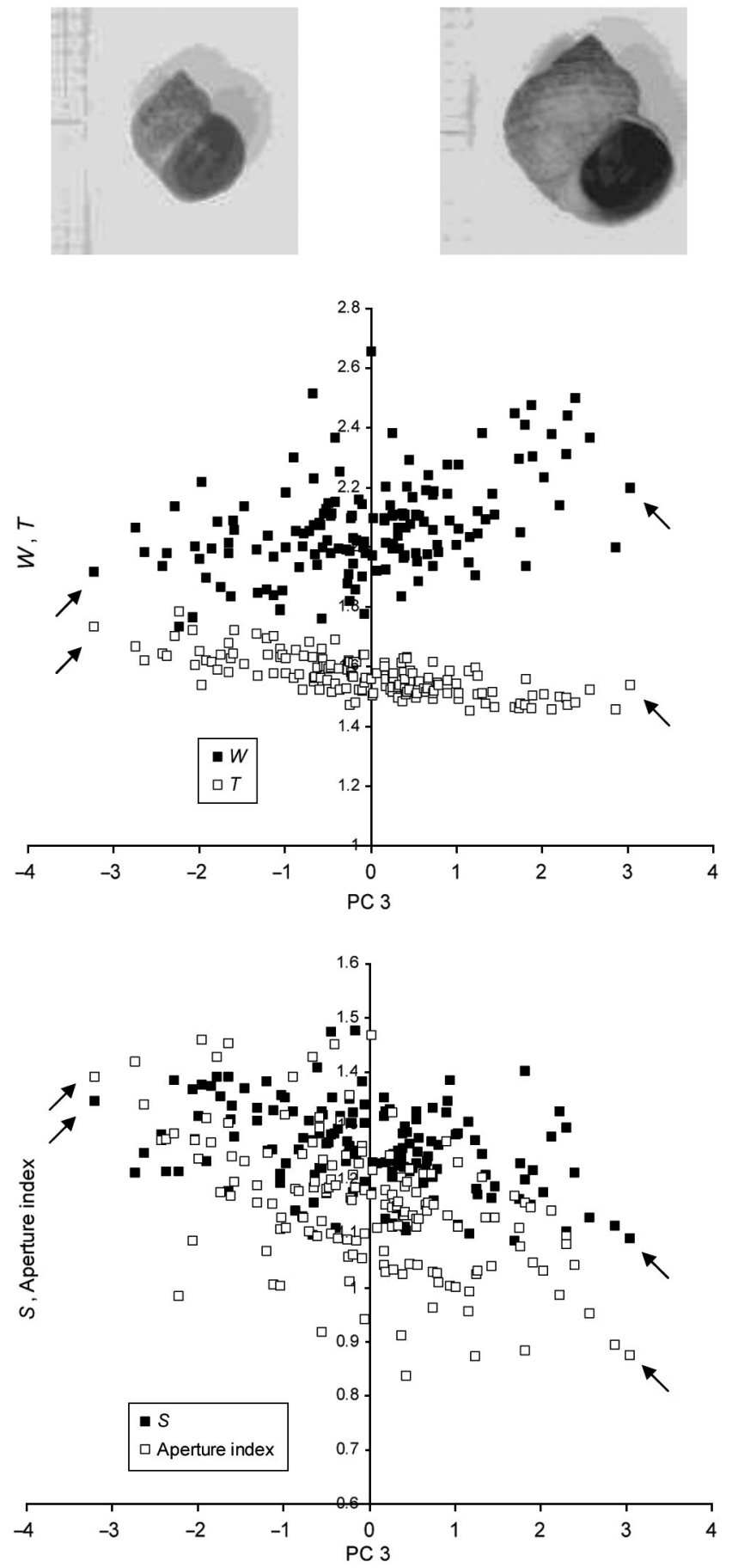

Fig. 4. Littorina saxatilis. Estimates of the Raup parameters $W$, $T$ and $S$ (see 'Materials and methods'), and also the metric of aperture index, plotted on scores for principal component (PC) 3. Example shells from the extremes of the component are shown; their positions on the plots are indicated by arrows
We illustrate the evident relationship between body index, RE and shape in Fig. 5, for the pooled data plotted on PC3. Brood index itself does not correlate with this PC, so that while the body index declines $(\rho=$ $-0.508, \mathrm{p}<0.001$, Table 2), RE estimated as the ratio of brood mass to body mass increases $(\rho=0.180, p=$ 0.027, Table 2).

Fig. 6 shows shell models calculated from the extended eigenshape analysis for EScs1, 3 and 4, revealing different aspects of the shell variation. PC1 is associated with variation in $T$, and ESc1 shows fluctuations in shell outline which appear symmetrical. EScs 3 and 4 are correlated with $\mathrm{PC} 3$; while the PCA points towards changes in $W, T$ and $S$, as well as aperture index, the eigenshape analysis of shell outlines appears to localise the variation asymmetrically on the lower whorls of the shell.

\section{DISCUSSION}

In 4 samples taken from 3 locations on the east Yorkshire coast, the shells of the high-shore form of Littorina saxatilis show consistent patterns of variation. Using shell dimensions which allow estimates of variables reflecting the parameters Raup (1966) used to describe molluscan shell growth, and comparing these with the results of PCA, we found that PC1 (the major aspect of variation in shell shape) is entirely related to changes in the whorl expansion rate, $W$. As the shells become relatively taller, with a lower $W$, the amount of tissue enclosed by the shell increases. We base this on finding an increase in the mass of tissue (either body or brood) as a ratio of the shell mass.

PC1 is evidently related to the axis of variation represented by ESc1 in an extended eigenshape analysis, as the correlation between the ordering of the shells on PC1 with that on ESc1 is very high (Table 4). As in the case of PC1, where everything that was happening appeared to be related to 1 Raup variable $(W)$, the variation on ESc1 is comparatively simple: there is an apparently symmetrical alteration in outline of the

Table 4. Spearman rank correlations between eigenscores (ESc) 1, 3 and 4 (see 'Materials and methods') and principal component (PC) scores, with both sets of scores calculated across all samples. Correlations with $\mathrm{p} \leq 0.013$ are shown in bold. This represents adjusting $\alpha$ to 0.013 . Correlations with p > 0.05 are not shown; therefore ESc2 has been omitted from the table

\begin{tabular}{|cccc|}
\hline & PC1 & PC2 & PC3 \\
ESc1 & $-\mathbf{0 . 9 2 5 ,} \mathbf{p}<\mathbf{0 . 0 0 1}$ & & \\
ESc3 & & $0.193, \mathrm{p}=0.017$ & $\mathbf{0 . 2 4 8 ,} \mathbf{p = 0 . 0 0 2}$ \\
ESc4 & & & $-\mathbf{0 . 2 9 7}, \mathbf{p}<\mathbf{0 . 0 0 1}$ \\
\hline
\end{tabular}




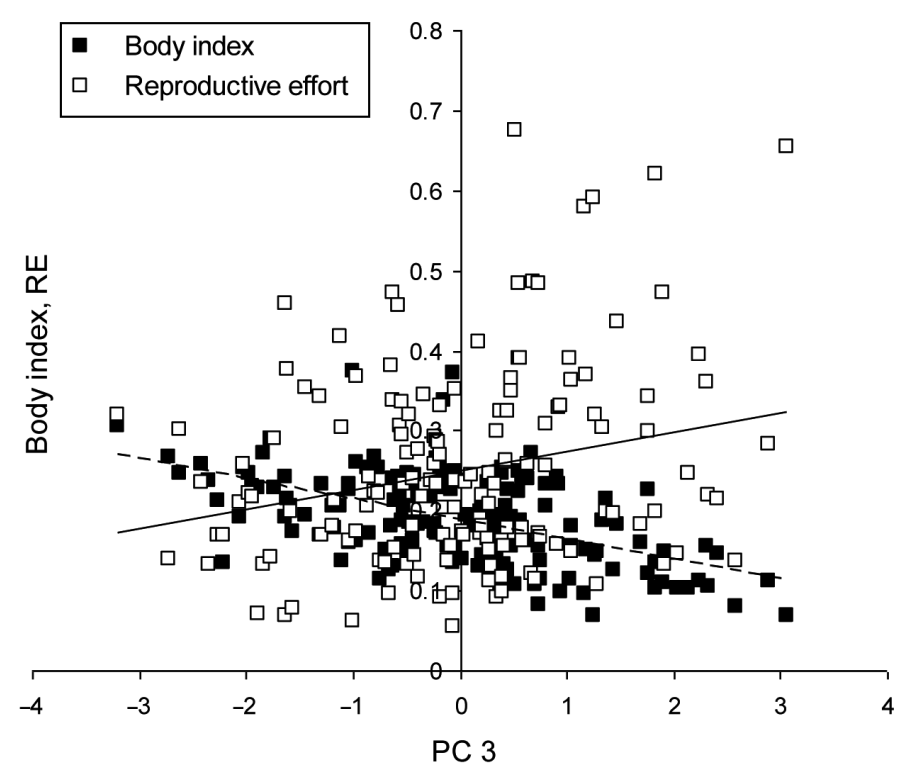

Fig. 5. Littorina saxatilis. Estimates of body index and reproductive effort (RE) plotted on principal component (PC) 3. Solid line: least squares slope for $\mathrm{RE}_{\text {; }}$ dashed line: least squares slope for body index
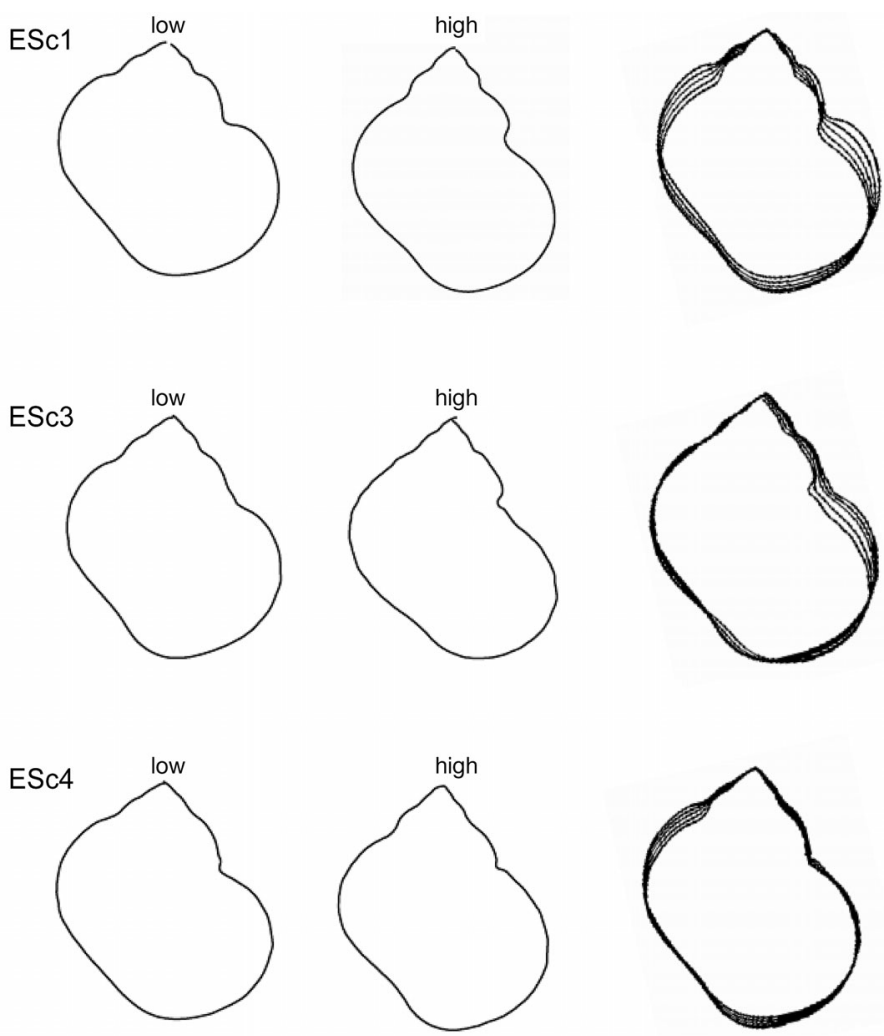

Fig. 6. Littorina saxatilis. Models of shell shape calculated from eigenscores (ESc) 1, 3 and 4 in an extended eigenshape analysis. The 2 extreme models are shown together with a superimposition of these with 3 intermediates shells (Fig. 6), again associated with changes in relative tissue mass estimates.

We did not explore PC2, as there seemed to be comparatively little biological interest there. PC3, however, is interesting, with changes in $T, W, S$ and aperture index. Paradoxically perhaps, with changes in both $T$ and $S$ the variation in shell form along PC3 appears less extreme than it does along PC1 (cf. Figs. 4 \& 3). This apparent paradox could be resolved if greater variability in the Raup parameters in some way buffered the overall shape changes. A point of difference between the $2 \mathrm{PCs}$ is that in the case of PC1, small $W$ is associated with a small aperture index (Fig. 3), while for PC3 the reverse is true (Fig. 4). On PC3, larger $W$ is associated with smaller and rounder apertures $(S$ nearer 1), whereas there is no consistent change in $S$ on PC1.

A common property of these 2 PCs is that on both, smaller $W$ is associated with a relatively larger body (judged by standardising body mass by dividing it by shell mass). However, and this may be a point of great biological interest, on PC3 there is only the slightest hint of a corresponding change in standardised brood mass; the correlation is $-0.130(p=0.109)$. This underlies the change in our estimate of RE, which increases along PC3 (Fig. 5) as $W$ increases, and $T, S$ and aperture index decrease (Fig. 4). There is a great deal of scatter in the points for RE (Fig. 5); nevertheless, we used the equation of the line of best fit for RE shown in the figure to obtain conservative estimates of a plausible change in RE. These are conservative because we used PC3 values of -2.5 and 2.5, well within the range of the data, and because there are many points above the line at around PC3 score of 2.5. The estimates are of RE values varying between 0.19 and 0.31 , representing an increase of about $63 \%$ of the smaller value. This implies a major shift in allocation to brood mass along the axis of variation represented by PC3. This is evidently a trade-off between the alternative functions of body and brood: presumably the reduction in body mass could be less severe if brood mass were similarly allowed to reduce along this axis of variation. It is worth emphasising that this is occurring on a very small spatial and indeed ecological scale: these data represent just 1 morph of Littorina saxatilis collected over a very small spatial scale, though replicated at 4 sample sites.

At least some of what we have found may be due to the individual experiences of the snails as they grew and matured; thus, there may be a phenotypic component involved. We cannot test this using our data, but it would seem likely on the basis of what is understood that there must be some genotypic component involved as well. A further caveat is that the dynamics of turnover of eggs and juveniles in the brood pouch of 
Littorina saxatilis are poorly understood, with embryos of early or late developmental stages present in widely varying proportions in different females (e.g. see Hull et al. 1999). In this circumstance, it is likely that a substantial amount of variation may be introduced into our estimate of reproductive effort from this source. This may explain at least some of the scatter evident in Fig. 5.

We suggest above that PC3 represents more complex interactions of the Raup parameters. Something similar seems to be the case with ESc4, which is correlated with it, and also with ESc3, which is also correlated with PC3 (although these 2 ESc axes are themselves uncorrelated; $\rho=0.022, p=0.790$ ). Whereas the shell models for ESc1 show what appears to be symmetric variation in outline between the left and right sides of the shell, that is not the case for ESc3 and ESc4 where the outline varies more on the right and the left side, respectively (Fig. 6). This is counterintuitive from a consideration of the Raup growth model, which suggests that the 2 'sides' of the shell should mirror one another. We cannot resolve this here, beyond making 2 suggestions. The first is that what appears in the shell models for ESc3 and ESc4 is in some way an artefact introduced by lack of control at the imaging stage, although if this were the case it would seem to be remarkable that there should then be such a strong signal in terms of the enclosed body and brood mass quantities. It would also seem to be the case that if positional error were involved, the shells on the 2 EScs should be correlated in order, but they are not.

The second suggestion is that there may be ontogenetic changes in the way the shell grows, perhaps to do with the need to accommodate a brood, so that there are biologically important (and variable) changes in allometric relations during growth. In this connection, it is worth noting that PC1 shows no correlation with the geometric mean size of the shells along it, while PC3 does $(\rho=0.248, p=0.002)$, as does ESc3 $(\rho=0.169$, $\mathrm{p}=0.037$, although the correlation of size with ESc4 is not significant $(\rho=-0.143, p=0.078)$. The possibility that the changes suggested by ESc3 and ESc4 may be a real phenomenon can be investigated by taking a wider size range of shells than was used here, which should reveal ontogenetic changes, and also perhaps by investigating males, which do not brood, or the high shore Littorina arcana, which also does not brood.

This work is an exploration of shell shape in a very small subset of the possible gastropod shapes, a subset restricted to 1 species living in a particular habitat. Our findings lead us to 2 different sorts of conclusion: firstly, we have demonstrated small and subtle changes in shape and its variation which yet seem to be associated with features of importance in the life of the animals. It would be fruitful to explore whether this is direct or through some intermediate variable(s). Secondly, in terms of methodology, the 3 ways of working with shell shape which we have employed - using PCA on linear dimensions between points on the shells, relating these to Raup growth parameters, and using extended eigenshape analysis - are complementary approaches which promise further enhancement of our understanding of the significance of shell shapes.

Acknowledgements. We thank J. Krieger for discussion of the eigenshape approach and for sharing workbooks with us. K. Johannesson and R. Gunton discussed various aspects of the work, and anonymous referees made valuable criticisms which have resulted in improvement of the manuscript.

\section{LITERATURE CITED}

Atkinson WD, Newbury SF (1984) The adaptations of the rough winkle, Littorina rudis, to desiccation and dislodgement by wind and waves. J Anim Ecol 53:93-105

Caley KJ, Grahame J, Mill PJ (1995) A geographically-based study of shell shape in small rough periwinkles. Hydrobiologia 309:181-193

Clarke RK, Grahame J, Mill PJ (1999) Variation and constraint in the shells of two sibling species of intertidal rough periwinkles (Gastropoda: Littorina spp.). J Zool (Lond) 247: 145-154

Conde-Padín P, Grahame JW, Rolan-Alvarez E (2007) Detecting shape differences in species of the Littorina saxatilis complex by morphometric analysis. J Molluscan Stud 73: 147-154

Conde-Padín P, Caballero A, Rolán-Alvarez E (2009) Relative role of genetic determination and plastic responses during ontogeny for shell-shape traits subjected to diversifying selection. Evolution 63:1356-1363

> Darroch JN, Mosimann JE (1985) Canonical and principal components of shape. Biometrika 72:241-252

Dytham C, Mill PJ, Grahame J, O'Higgins P (1992) Fourier analysis as a size-free descriptor of shape for rough periwinkles. In: Grahame J, Mill PJ, Reid DG (eds) Proc 3rd Int Symp Littorinid Biol. The Malacological Society, London, p $127-133$

Grahame J, Mill PJ (1986) Relative size of the foot of two species of Littorina on a rocky shore in Wales. J Zool (Lond) 208:229-236

Grahame J, Mill PJ (1989) Shell shape variation in Littorina saxatilis and Littorina arcana: a case of character displacement? J Mar Biol Assoc UK 69:837-855

> Grahame J, Mill PJ, Brown AC (1990) Adaptive and nonadaptive variation in two species of rough periwinkle (Littorina) on British shores. Hydrobiologia 193:223-231

Grahame JW, Wilding CS, Butlin RK (2006) Adaptation to a steep environmental gradient and an associated barrier to gene exchange in Littorina saxatilis. Evolution 60:268-278

Hart A, Begon M (1982) The status of general reproductivestrategy theories, illustrated in winkles. Oecologia 52:37-42

Hughes RN (1995) Resource allocation, demography and the radiation of life histories in rough periwinkles (Gastopoda [sic]). Hydrobiologia 309:1-14

Hughes RN, Roberts DJ (1980) Reproductive effort of winkles (Littorina spp.) with contrasted methods of reproduction. Oecologia 47:130-136

Hull SL, Grahame J, Mill PJ (1999) Reproduction in four populations of brooding periwinkle (Littorina) at Ravenscar, 
North Yorkshire: adaptation to the local environment? J Mar Biol Assoc UK 79:891-898

Jungers WL, Falsetti AB, Wall CE (1995) Shape, relative size, and size-adjustments in morphometrics. Yearb Phys Anthropol 38:137-161

Krieger JD, Guralnick RP, Smith DM (2007) Generating empirically determined, continuous measures of leaf shape for paleoclimate reconstruction. Palaios 22:212-219

MacLeod N (1999) Generalizing and extending the eigenshape method of shape space visualization and analysis. Paleobiology 25:107-138

Moran MD (2003) Arguments for rejecting the sequential Bonferroni in ecological studies. Oikos 100:403-405

R Development Core Team (2010) R: a language and en-

Submitted: August 9, 2010; Accepted: March 7, 2011 vironment for statistical computing. Foundation for Statistical Computing, Vienna. Available at www.R-project.org (accessed January 2009)

Raup DM (1966) Geometric analysis of shell coiling: general problems. J Paleontol 40:1178-1190

Reid DG (1996) Systematics and evolution of Littorina. The Ray Society, Dorchester

Rohlf FJ (1996) Morphometrics at SUNY Stony Brook. Available at http://life.bio.sunysb.edu/morph/index.html (accessed January 2009)

Rosenthal R (1978) Combining results of independent studies. Psychol Bull 85:185-193

SAS Institute (1990) SAS/STAT ${ }^{\circledR}$ users guide, version 6, 4th edn, Vols 1 \& 2. SAS Institute, Cary, NC

Proofs received from author(s): May 12, 2011 